\title{
Anticonvulsant and proconvulsant roles of nitric oxide in experimental epilepsy models
}

E.A. Del-Bel2,

P.R. Oliveira ${ }^{1}$,

J.A.C. Oliveira ${ }^{1}$,

P.K. Mishra ${ }^{3}$,

P.C. Jobe ${ }^{3}$ and

N. Garcia-Cairasco ${ }^{1}$

\begin{abstract}
'Laboratório de Neurofisiologia e Neuroetologia Experimental, Departamento de Fisiologia, Faculdade de Medicina de Ribeirão Preto and ${ }^{2}$ Departamento de Fisiologia, Faculdade de Odontologia de Ribeirão Preto, Universidade de São Paulo, 14049-900 Ribeirão Preto, SP, Brasil

${ }^{3}$ Laboratory of Neurological and Behavioral Disorders, Department of Pharmacological and Therapeutical Sciences, University of Illinois, College of Medicine at Peoria, Peoria, IL 61656-1649, USA
\end{abstract}

\section{Correspondence \\ N. Garcia-Cairasco \\ Laboratório de Neurofisiologia \\ e Neuroetologia Experimental \\ Departamento de Fisiologia \\ FMRP, USP \\ 14049-900 Ribeirão Preto, SP \\ Brasil \\ Fax: 55 (016) 633-0017 \\ E-mail: ngcairas@fmrp.usp.br}

Research supported by FAPESP (Nos. 92/4464-3 and 95/95006)

and CNPq (No. 521596/94).

$\ldots \ldots \ldots \ldots \ldots \ldots \ldots$

Received October 23, 1996

Accepted June 13, 1997

$\ldots \ldots \ldots \ldots \ldots \ldots \ldots$

\begin{abstract}
The effect of acute $(120 \mathrm{mg} / \mathrm{kg})$ and chronic $(25 \mathrm{mg} / \mathrm{kg}$, twice a day, for 4 days) intraperitonial injection of the nitric oxide (NO) synthase (NOS) inhibitor $\mathrm{N}^{\mathrm{G}}$-nitro-L-arginine (L-NOARG) was evaluated on seizure induction by drugs such as pilocarpine and pentylenetetrazole (PTZ) and by sound stimulation of audiogenic seizure-resistant (R) and audiogenic seizure-susceptible (S) rats. Seizures were elicited by a subconvulsant dose of pilocarpine $(100 \mathrm{mg} / \mathrm{kg})$ only after NOS inhibition. NOS inhibition also simultaneously potentiated the severity of PTZ-induced limbic seizures $(60 \mathrm{mg} / \mathrm{kg}$ ) and protected against PTZ-induced tonic seizures $(80 \mathrm{mg} / \mathrm{kg})$. The audiogenic seizure susceptibility of S or R rats did not change after similar treatments. In conclusion, proconvulsant effects of NOS inhibition are suggested to occur in the pilocarpine model and in the limbic components of PTZinduced seizures, while an anticonvulsant role is suggested for the tonic seizures induced by higher doses of PTZ, revealing inhibitorspecific interactions with convulsant dose and also confirming the hypothesis that the effects of NOS inhibitors vary with the model of seizure.
\end{abstract}

\section{Introduction}

Epilepsy is a phenomenon causing severe and continuous seizure activity such as that present in status epilepticus, or chronic spontaneous recurrent seizures. Alterations in several classic neurotransmitter systems such as the glutamatergic (1) or GABAergic (2) one have been implicated in the elicitation of epileptic seizures. More recently, other molecules such as nitric oxide (NO) have been pointed out as potential neurotransmitters or retrograde messengers (3) linked to synaptic plasticity (4) and regulation of brain excitability, including the triggering of seizure activity $(5,6)$.

$\mathrm{NO}$ is formed from L-arginine by the enzyme NO synthase (NOS) (7) and the involvement of $\mathrm{NO}$ in epileptic disorders has been shown in experiments with systemic injection of NOS inhibitors $(5,6,8,9)$. However, NOS inhibitor treatment has been reported either to augment $(6,8,9)$ or to inhibit (6,10-13) experimentally induced seizures. 
Mollace et al. (14) reported that L-arginine increased seizure severity in response to a subconvulsive dose of NMDA, suggesting that NO is a proconvulsant mediator. In contrast, during bicuculline-induced seizures, inhibition of NOS doubled the duration of the seizures $(13,15)$. Inhibition of NOS attenuated kainate- (16) and tacrine-induced (17) convulsions, while in other studies NOS inhibition increased the severity of seizures and mortality during status epilepticus $(12,18)$. Similar to the effect of NOS inhibitors during stroke, it is fair to assume that the discrepancies in the experimental findings may be due to the fact that the anti- or proconvulsant activity of NOS inhibitors is dose dependent, with lower doses affording protection (19). The alternative neurodestructive and neuroprotective roles of NO have been the subject of intense debate (reviewed by Choi $(20) ; 21,22)$. The relative predominance of each effect has been ascribed to the physicochemical redox state of the NO molecule $(23,24)$, to its tissue concentration (21) or to whether it was synthesized neuronally or in the cerebral vasculature $(25,26)$. These factors might also influence the effects of NO on excitatory and inhibitory processes evoked by seizures, with varying results that might be difficult to predict.

The main goals of the present study were to obtain a better understanding of $\mathrm{NO}$ effects on seizures in order to determine if contradictory pro- and anticonvulsant results from the literature were due to the use of different epilepsy models. Assuming that these effects could be either neuroprotection or potentiation of seizures, we looked for seizure models that could show positive and negative effects. Pentylenetetrazole (PTZ)evoked seizures can be either of the limbic type or generalized tonic-clonic seizures, depending on the dose of PTZ used. Additionally, pilocarpine (PILO) is able to induce acute limbic status epilepticus and complex partial type of seizures in the chronic state, when recurrent spontaneous seizures appear
$(27,28)$. Subconvulsant PILO doses can be used in order to test the blocking effect of NOS on limbic seizure facilitation (9). Audiogenic genetically epilepsy-prone rats (GEPR-3s), Wistar and Sprague-Dawley resistant rats can be used to test seizure increase or de novo appearance after the treatments, whereas GEPR-3s and susceptible Wistar animals can be used to test the reduction in audiogenic seizure, which may suggest an involvement of NO in generalized tonic-clonic seizures $(29,30)$. The seizure models currently used have common and distinct mechanisms. Limbic seizures are generally evoked by activation of forebrain excitatory mechanisms (31), while tonic-clonic seizures are related to GABA dysfunctions (PTZ) or to genetic (GABA and excitatory amino acids) alterations and sound sensitivity (audiogenic rats) $(29,32)$.

\section{Material and Methods}

\section{Animals}

Adult male rats (200-300 g) were maintained on a constant 12/12-h light/dark cycle, with free access to food and water.

Group 1. Wistar rats received a subconvulsant dose of PILO $(100 \mathrm{mg} / \mathrm{kg}$, ip $)$ and were treated acutely with either $0.9 \%$ saline $(\mathrm{N}=7)$ or $\mathrm{N}^{\mathrm{G}}$-nitro-L-arginine (L-NOARG, ip) $(\mathrm{N}=8)$.

Group 2. Wistar rats received a subconvulsant dose of PILO (100 mg/kg, ip $)$ and were treated chronically with either $0.9 \%$ saline $(\mathrm{N}=7)$ or L-NOARG $(\mathrm{N}=6)$.

Group 3. Wistar rats received subconvulsant doses of PTZ (15 and $30 \mathrm{mg} / \mathrm{kg}$, ip), or convulsant doses of PTZ (60 and $80 \mathrm{mg} / \mathrm{kg}$, ip) and were treated acutely with L-NOARG ( $\mathrm{N}=8$ for each dose).

Group 4. Wistar rats received subconvulsant doses of PTZ (15 and $30 \mathrm{mg} / \mathrm{kg}$, ip $)$, or convulsant doses of PTZ (60 and $80 \mathrm{mg} / \mathrm{kg}$, ip) and were treated acutely with $0.9 \%$ saline 
( $\mathrm{N}=8$ for each subgroup).

Group 5. GEPR-3s and Sprague-Dawley control rats were submitted to acoustic stimulation, and treated acutely with either L-NOARG or $0.9 \%$ saline $(\mathrm{N}=6$ for each group).

Group 6. GEPR-3s and Sprague-Dawley control rats were submitted to acoustic stimulation and treated chronically with either L-NOARG or $0.9 \%$ saline ( $\mathrm{N}=6$ for each group).

Group 7. Wistar audiogenic resistant rats were submitted to acoustic stimulation and treated acutely with either $0.9 \%$ saline $(\mathrm{N}=8)$ or L-NOARG $(\mathrm{N}=6)$.

Group 8. Wistar audiogenic resistant rats were submitted to acoustic stimulation and treated chronically with either $0.9 \%$ saline $(\mathrm{N}=7)$ or L-NOARG $(\mathrm{N}=8)$.

All experiments were performed in accordance with the rules of the Brazilian Society for Neuroscience and Behavior for animal experimentation.

\section{Drugs}

All drugs were purchased from Sigma Chemical Co. (St. Louis, MO). L-NOARG, PILO, methyl-scopolamine and PTZ were dissolved in sterile saline $(0.9 \%)$. The systemic treatments were performed in a volume of $1 \mathrm{ml} / \mathrm{kg}$ body weight.

\section{Treatments}

Acute. Animals received L-NOARG (120 $\mathrm{mg} / \mathrm{kg}$, ip) or saline $(0.9 \%)$ and 30 min later a dose of the convulsant drug (PILO or PTZ groups) or sound stimulation (audiogenic seizure (AS) groups).

Chronic. Animals were chronically treated with saline $(0.9 \%)$ or L-NOARG $(25$ $\mathrm{mg} / \mathrm{kg}$, ip), twice a day for 4 days, and received a dose of one of the convulsant drugs or sound stimulation $30 \mathrm{~min}$ after the last injection.

\section{Seizure models}

Pilocarpine limbic seizures. Rats (groups 1 and 2) were injected with PILO nitrate $(100 \mathrm{mg} / \mathrm{kg}$, ip) or $380 \mathrm{mg} / \mathrm{kg}$, ip, preceded by $1 \mathrm{mg} / \mathrm{kg}$ methyl-scopolamine in order to decrease peripheral cholinergic side effects.

PTZ-induced tonic-clonic seizures. Both subconvulsant (15 and $30 \mathrm{mg} / \mathrm{kg}$, ip) and convulsant (60 and $80 \mathrm{mg} / \mathrm{kg}$, ip) doses of PTZ were injected into adult Wistar rats.

Audiogenic seizures. Wistar and SpragueDawley resistant (R) animals, as well as susceptible (S) GEPR-3s were exposed to high-intensity $(120 \mathrm{~dB})$ acoustic stimulation for a maximum of $1 \mathrm{~min}$ or until tonic-clonic seizures appeared. Latencies and seizure severity indexes were then calculated.

\section{Behavioral evaluation of seizure activity}

Limbic seizures. To score limbic patterns such as those evoked by PILO or PTZ, we used the Racine (33) scale (classes 0 to 5) of limbic seizures as follows: $0=$ immobility, 1 = facial automatisms, $2=$ head nodding, $3=$ unilateral forelimb clonus/bilateral forelimb clonus, $4=$ bilateral forelimb clonus and rearing, and $5=$ rearing, falling and generalized convulsions.

Audiogenic seizures. For the evaluation of audiogenic seizures (AS) in Wistar rats, an audiogenic severity index (SI), including a graded linear scale with a range of severity from $\mathrm{SI}=0$ (resistant rats) to $\mathrm{SI}=1.0$ (maximum, susceptible rats), was calculated (30). In order to determine the audiogenic susceptibility of the animals, three acoustic stimulations were performed before the beginning of the experimental protocol. For the Wistar animals, the most frequent behavioral sequences gave SI of the following values, which are derived from an audiogenic severity index we developed (30,34): 1) wild running (one fit) (SI $=0.11) ; 2$ ) wild running with atonic falling and jumping during the running fits (SI = 
Figure 1 - Proconvulsant effects of L-NOARG on a subconvulsant pilocarpine $(100 \mathrm{mg} / \mathrm{kg}$, ip) dose. Observe the incidence of salivation (A), piloerection (B), facial automatisms (C) and status epilepticus (D) after acute or chronic L-NOARG treatment $\left({ }^{*} \mathrm{P}<0.05\right.$; ${ }^{*} \mathrm{P}<0.001$; Fisher exact test).

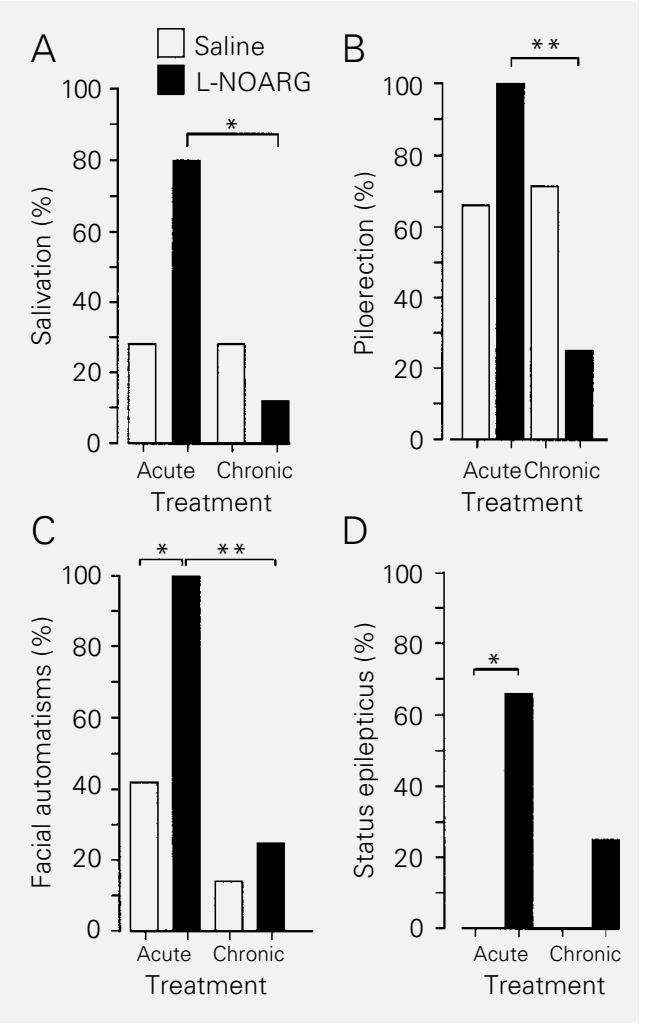

0.23); 3) wild running (two fits), atonic falling, and jumping ( $\mathrm{SI}=0.38) ; 4$ ) all the above plus tonic seizures (TCV; back arching tonus) (SI = $0.61)$; 5) all the above plus partial (only forelegs or hindlegs) and generalized (forelegs and hindlegs) clonic seizures ( $\mathrm{SI}=0.73)$; 6 ) all the above plus clonic spasms $(\mathrm{SI}=0.85) ; 7)$ all the above plus head ventral flexion $(\mathrm{SI}=0.9) ; 8$ ) all the above plus forelimb hyperextension (SI $=0.95$ ), and 9) all the above plus hindlimb hyperextension $(\mathrm{SI}=1.0)$. The same SI was used for the highest PTZ doses because the induced seizures usually ended with wild running followed by tonic hyperextensions. For the GEPR-3s, which are derived from SpragueDawley colonies, seizure severity was calculated using the audiogenic response scores (ARS) (0 to 9) described by Jobe et al. (29).

In the chemical models, latencies to the beginning of the seizure activity, and frequency of a given behavior were evaluated for $1 \mathrm{~h}$. We mainly recorded the presence of piloerection, salivation, facial automatisms, myoclonus and status epilepticus, evaluated only by visual inspection. These behaviors have been widely described in previous experiments of the PILO model $(27,28,35)$. In the case of audiogenic seizures, latency to running and to convulsion were also evaluated when present.

\section{Statistical analysis}

Incidence (\%) of a given behavior was evaluated by the Fisher exact test $(\mathrm{P}<0.05)$. The values of the Racine scale or SI and ARS before and after treatments were compared by MANOVA.

\section{Results}

Pilocarpine $(380 \mathrm{mg} / \mathrm{kg}$, ip $)$ elicited status epilepticus, followed by animal death (data not shown). No treatment was used (valium or thionembutal) to favor animal survival after status epilepticus because our main goal was to study only seizures induced by a high dose of PILO and by acute and chronic low doses of PILO. For this reason, all the animals treated with $380 \mathrm{mg} / \mathrm{kg}$ PILO died or were sacrificed after treatment. We did not intend to save the animals for spontaneous recurrent seizures.

A subconvulsant dose of PILO (100 mg/ $\mathrm{kg}$ ) induced behavioral modifications such as salivation, piloerection and facial automatisms, although this dose was not sufficient to elicit status epilepticus (0/14 animals; Figure 1). Acute pretreatment with L-NOARG of PILO-injected rats $(100 \mathrm{mg} / \mathrm{kg})$ strongly increased salivation (Figure 1A), piloerection (Figure 1B), and facial automatisms $(\mathrm{P}<0.05$, Fisher exact test; Figure 1C). These effects were less pronounced in the chronically L-NOARG-treated group (Figure 1A, $\mathrm{P}<0.05 ; 1 \mathrm{~B}$ and $1 \mathrm{C}, \mathrm{P}<0.01)$. Status epilepticus was induced by PILO $(100 \mathrm{mg} /$ $\mathrm{kg}$ ) in both the acutely and chronically LNOARG-treated groups (Figure 1D), with a significant effect being observed in the 
acutely treated group $(\mathrm{P}<0.05)$. It is important to note that acute or chronic saline or LNOARG treatment alone did not induce any seizures (groups 1 and 2) before PILO or any other treatment.

Class 4-5 limbic seizures (Racine scale) were induced by a subconvulsant PILO dose $(100 \mathrm{mg} / \mathrm{kg})$ after both acute and chronic LNOARG treatment $(\mathrm{P}<0.01$, MANOVA; Figure 2). Observe in the same figure that, surprisingly, PILO alone also induced partial myoclonus (class $1-2 ; \mathrm{P}<0.05$ ) in the acute but not in the chronic group.

Behavioral alterations were not observed in rats submitted to NOS blockade and treated with the subconvulsant PTZ doses (15 and $30 \mathrm{mg} / \mathrm{kg}$, Figure 3). However, the PTZ dose of $60 \mathrm{mg} / \mathrm{kg}$ induced class 4-5 limbic seizures (Figure 3), which were significantly worsened by acute L-NOARG treatment ( $<<0.01$; MANOVA). The $80 \mathrm{mg} / \mathrm{kg}$ PTZ dose, a lethal dose, produced myoclonic jerks, generalized clonic seizures and tonic generalized extension, followed by animal death. Previous L-NOARG treatment significantly suppressed the incidence of tonic seizures and status epilepticus (Figure 4), and the severity of tonic seizures (Figure 5). In summary, these results demonstrate that NOS inhibition can exert both anticonvulsant and proconvulsant effects in the same epilepsy model (PTZ), depending on the convulsant dose used.

Audiogenic seizure-resistant rats (both Wistar and Sprague-Dawley) did not modify their behavior after L-NOARG-induced systemic NOS blockade and further acoustic stimulation (data not shown). Also, GEPR$3 \mathrm{~s}$, which are susceptible to audiogenic seizures, did not present changes in severity indexes or mean latencies to wild running or tonic-clonic seizure after acute or chronic LNOARG treatment (data not shown).

\section{Discussion}

The present data demonstrate that the

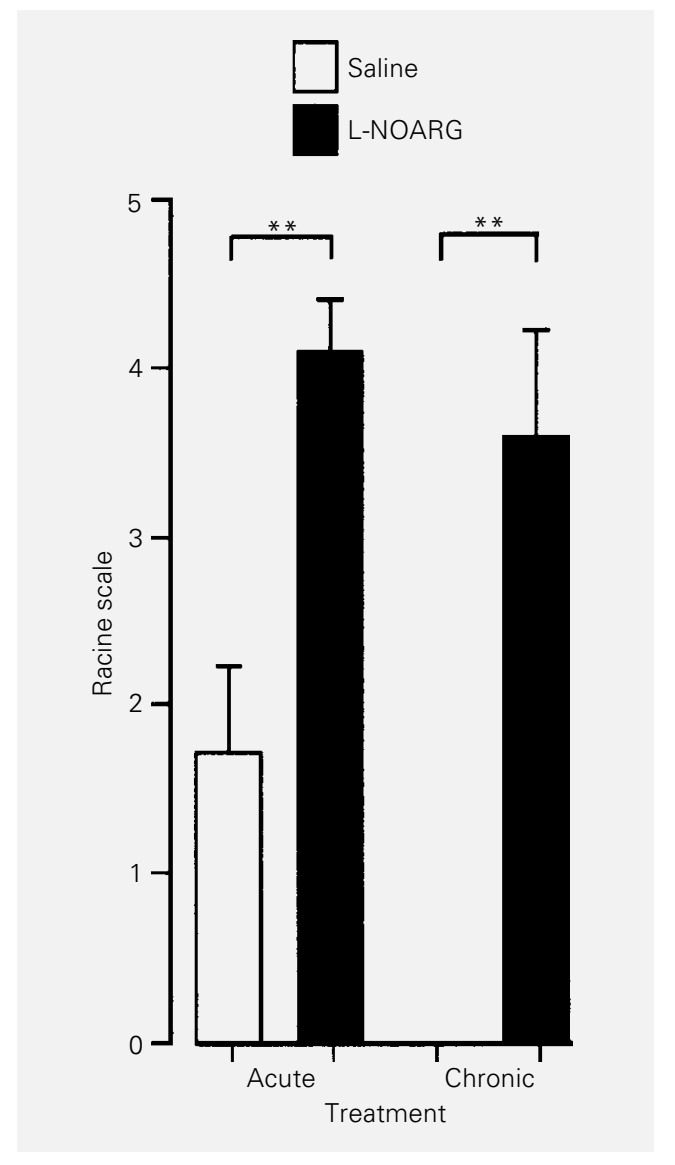

Figure 2 - Proconvulsant effects of acute or chronic L-NOARG treatment on a subconvulsant dose of pilocarpine $(100 \mathrm{mg} / \mathrm{kg}$, ip). Animals were evaluated for limbic seizures by the Racine scale $\left({ }^{*} P<0.05 ; \quad *{ }^{*} P<0.01\right.$; MANOVA). effects of NOS inhibition and consequently the inhibition of NO synthesis on seizure activity depend on the seizure model (sensory or chemical) and, in the case of chemical induction, on the type and dose of the convulsant drug.

As far as we know, this is the first demonstration that the same dose of the NOS inhibitor L-NOARG can exert both anticonvulsant and proconvulsant effects on PTZevoked seizures. Thus, we suggest that seizure activity can be modulated by $\mathrm{NO}$ in different ways by means of either proconvulsant (PILO- and PTZ-evoked limbic seizures) or anticonvulsant (status epilepticus, tonic seizures and death evoked by the highest doses of PTZ) actions.

Limbic seizure potentiation was observed after acute L-NOARG treatment in the animals treated with the $100 \mathrm{mg} / \mathrm{kg}$ PILO dose and the $60 \mathrm{mg} / \mathrm{kg}$ PTZ dose. No effect of L- 
Figure 3 - Effect of L-NOARG treatment on PTZ-induced seizures. Note that potentiation of limbic seizures by L-NOARG treatment only occurred at the $60 \mathrm{mg} / \mathrm{kg}$ dose. Animals were evaluated for limbic seizures by the Racine scale ( ${ }^{*} P<0.05$; ${ }^{*} P<0.01$; MANOVA). Note that $30 \mathrm{mg} / \mathrm{kg}$ PTZ elicited no limbic seizures (Racine scale $=0$ ).
Figure 4 - Percentage of tonic convulsion (TCV), status epilepticus and fatalities after pretreatment with L-NOARG of PTZ (80 mg/kg)-injected animals $\left({ }^{*} \mathrm{P}<0.05\right.$; ${ }^{*} \mathrm{P}<0.001$; Fisher exact test). See also Figure 5.
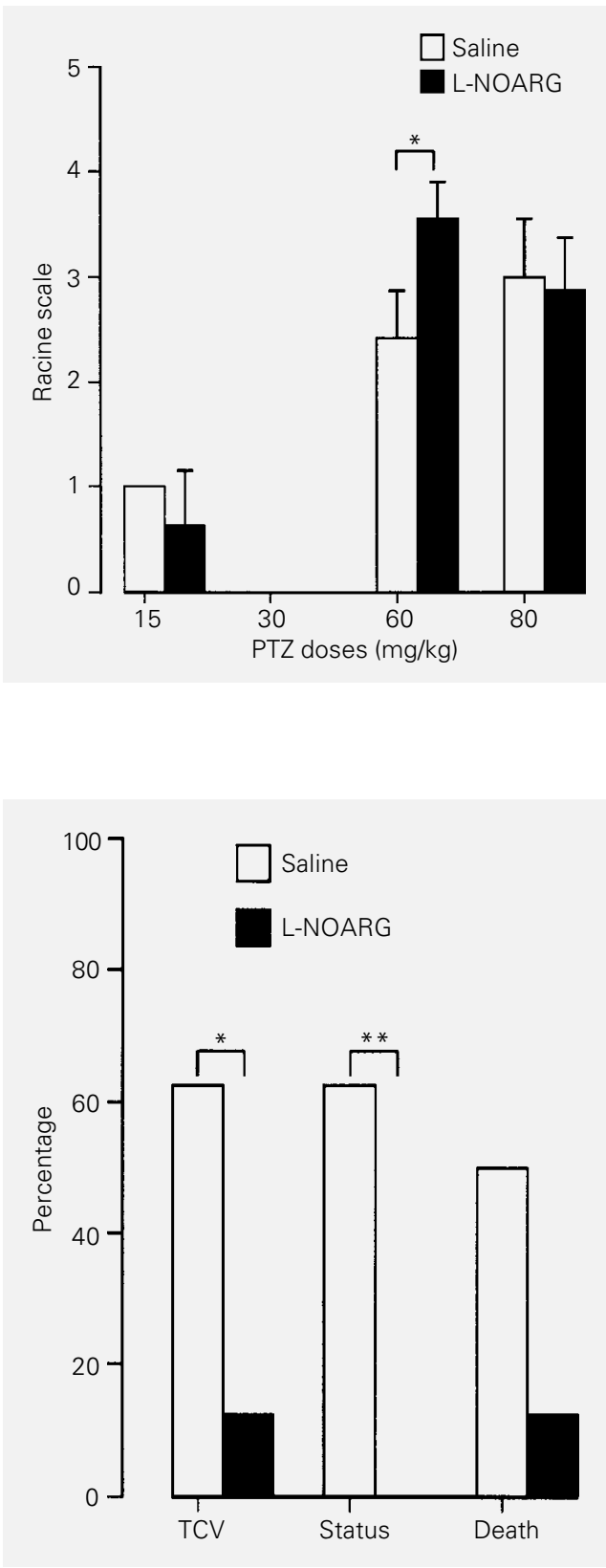

NOARG treatment was found with the 15 and $30 \mathrm{mg} / \mathrm{kg}$ dose of PTZ. Anticonvulsant L-NOARG effects were observed with PTZinduced tonic seizures.

The doses of L-NOARG used in the present study were generally higher than those reported to protect against ischemic or excitotoxic lesions $(5,36)$. The drug treatment regimen used in this study produced a substantial reduction of NO synthesis. It has been previously shown that a single injection of L-NOARG produces 50\% inhibition and that four days of administration produce $95 \%$ inhibition of NO synthase $(37,38)$. Moreover, drugs were given at doses that were previously shown to affect behavior (39-43) or seizure activity $(9,44)$. These findings suggest that the effect of L-NOARG on seizure models involves a decrease in NO formation in the CNS.

Furthermore, although the L-NOARG doses of the present experiments have been commonly employed in the literature, some studies have found inverted U-shaped doseresponse curves for various NOS inhibitors (42). Therefore, it would be interesting to test additional doses of L-NOARG in the epilepsy models used in our study.

It is interesting to note that in the present study there was a difference between acute and chronic L-NOARG treatment. Acute LNOARG treatment had a facilitatory effect on a subconvulsant PILO dose $(100 \mathrm{mg} / \mathrm{kg})$ for facial automatisms and status epilepticus. Additionally, salivation, piloerection and facial automatisms decreased significantly after chronic L-NOARG treatment. This is in agreement with recent data on catalepsy induced by acute L-NOARG treatment, although catalepsy was significantly decreased after chronic administration of the drug (42). These data contrast with other studies showing no difference between the acute and chronic effect of L-NOARG on the prolongation of bicuculline-induced seizures (13) and potentiation of kainic acid-induced seizures (8).

The protective effect of the acute LNOARG treatment on the tonic seizures induced by $80 \mathrm{mg} / \mathrm{kg}$ PTZ is in agreement with data from Osonoe et al. (11) who examined the effect of systemic injection of L-NAME and L-NOARG on PTZ-induced seizures, reaching the conclusion that both drugs preferentially suppressed tonic generalized extension and prolonged its onset latency. Initiation and generalization of PTZ-induced 
seizures are related to the activation of NMDA receptors (45) and to competitive inhibition of GABA neurotransmission. GABA and NMDA increase intracellular $\mathrm{Ca}^{2+}$, which activates NO synthase. Thus, LNOARG inhibition of NO synthase could help suppress the tonic component of PTZinduced seizures, protecting against their lethal effect. These results support the suggestion that NO contributes to the genesis of limbic seizure activity.

The effects of L-NOARG on limbic seizure models (PILO) and the tonic component of PTZ-induced seizures are in contrast to the lack of interference of L-NOARG with GEPR-3s audiogenic seizure, a model of brainstem-dependent seizures (29). Interestingly, a recent publication on kainate-induced behavioral and electrographic seizures in mice (46) demonstrated that L-NAME can display proconvulsant effects depending on the route of administration of the kainate (either systemic or intra-hippocampal). An intriguing fact is that L-NAME potentiated kainate-induced wild running, but not necessarily clonus (limbic pattern), suggesting the involvement of brainstem mechanisms.

The behavioral expression of audiogenic seizures, a model of genetically dependent generalized tonic-clonic seizures, seems to depend almost exclusively on brainstem substrates $(29,30)$. Among other mechanisms, inferior colliculus NMDA neurotransmission plays a critical role in the expression of AS (47). Because there is a potent link between NMDA activity and NO synthesis (23), we expected to obtain some effects from the L-NOARG treatment of AS-resistant or -susceptible rats. Recently, however, Grassi et al. (48) have shown that, although microinfusion of L-NAME into the inferior colliculus was able to reduce middle latency auditory evoked responses (thalamo-cortical generators), the same treatment did not change the midbrain-evoked responses, particularly the collicular component (wave V). Additionally, Iannone et al. (49) also showed

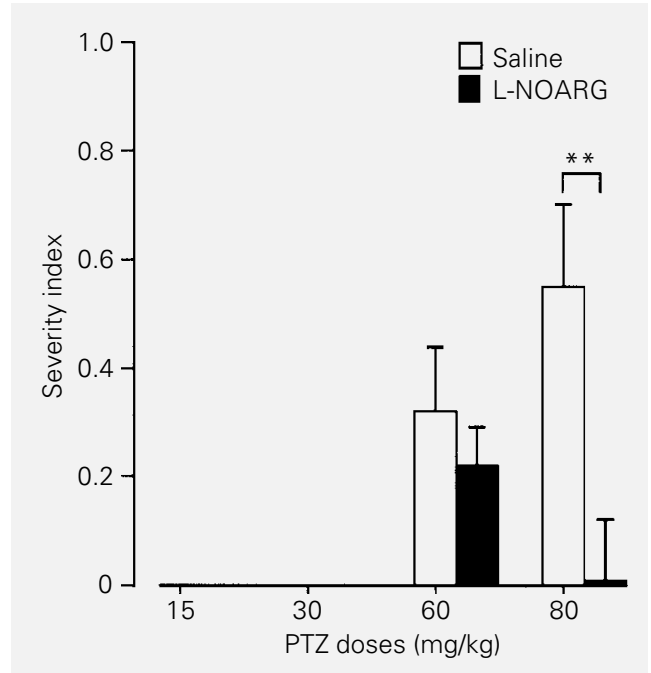

Figure 5 - Effect of L-NOARG pretreatment on the brainstem component of PTZ $(80 \mathrm{mg} / \mathrm{kg})$ induced seizures. This severity index (SI) $(30,34)$ includes tonic extensions (see Methods) as the end point of convulsive activity. Observe the clear protection against this tonic activity by $\mathrm{L}$ NOARG $\left({ }^{*} \mathrm{P}<0.05 ;{ }^{*} \mathrm{P}<0.01\right.$; MANOVA). See also Figure 4 Note that $15 \mathrm{mg} / \mathrm{kg}$ and $30 \mathrm{mg} /$ kg PTZ had no effect on tonicclonic seizures $(S I=0)$. that L-NAME induced a blockade of electrocortical desynchronization, an effect which is compatible with telencephalic activity. Thus, experiments involving microinjection of either L-NOARG or L-NAME into the inferior colliculus are necessary in order to rule out NO participation in AS. The present data, based on L-NOARG systemic treatment, did not show any clear involvement of $\mathrm{NO}$ in AS.

At the moment it is not possible to explain the molecular mechanisms responsible for the effect of L-NOARG on seizures. Acute effects of NO might involve an influence of NO on NMDA-mediated neurotransmission. NO has a complex influence on this neurotransmission. For example, it may mediate the NMDA-induced increase in cGMP but simultaneously inhibit the NMDA-induced increase in intracellular $\mathrm{Ca}^{2+}$ and NOS activity, and block NMDA receptors $(20,23)$. The influence of NO on NMDA neurotransmission may vary widely according to drug concentration and site of injection, which might explain the range of conflicting results on the role of NO in NMDA-modulated events such as epilepsy, neurotoxicity, longterm potentiation and nociception $(5,20$, 50,51). For instance, in a very recent study Proctor et al. (52) demonstrated that exogenously applied NO or its precursors can 
enhance seizure-triggering activity. However, in an NMDA-dependent focally evoked seizure model (activation of the area tempestas), they demonstrated that the L-arginine-nitric oxide pathway does not normally contribute to seizure expression from the area tempestas.

This biphasic effect of NOS inhibitors is not unusual for drugs with anticonvulsant activity (53). Moreover, the dual role of NOS inhibitors was observed in studies of experimental anxiety (41), paradoxical results which we may extend to those obtained with NOS inhibitors in the current animal models of epileptic seizures.

The present experiments confirm that $\mathrm{NO}$ is clearly involved in seizure modulation through a complex set of mechanisms in- cluding both proconvulsant and anticonvulsant capabilities. Thus, our data suggest a dual role for NO in seizure modulation, which seems to be dependent on the epilepsy model and, in the case of drugs, on the dose actually used. An understanding of the molecular mechanisms of this dual active pro- and anticonvulsant effect depends on more specific protocols which we are currently developing in our laboratories.

\section{Acknowledgment}

We thank Donna Birkhann, Peoria, IL, USA for technical assistance with the GEPR3 s colony.

\section{References}

1. Mody | \& Heinemann U (1987). NMDA receptors of dentate gyrus granule cells participate in synaptic transmission following kindling. Nature, 326: 701-704.

2. Babb TL, Pretorius JK, Kupfer WR \& Crandall PH (1989). Glutamate decarboxylase-immunoreactive neurons are preserved in human epileptic hippocampus. Journal of Neuroscience, 9: 2562-2574.

3. Moncada S, Palmer RMJ \& Higgs EA (1991). Nitric oxide: physiology, pathophysiology, and pharmacology. Pharmacological Reviews, 43: 109-142.

4. Dinerman JL, Dawson TM, Schell MJ \& Snowman A (1994). Endothelial nitric oxide synthase localized to hippocampal pyramidal cells: Implications for synaptic plasticity. Neurobiology, 91: 4214-4218.

5. Buisson A, Lakhmeche N, Verrecchia C, Plotkine M \& Boulu RG (1993). Nitric oxide: an endogenous anticonvulsant substance. NeuroReport, 4: 444-446.

6. Rondouin G, Bockaert J \& Lerner-Natoli $M$ (1993). L-Nitroarginine, an inhibitor of NO synthase dramatically worsens limbic epilepsy in rats. NeuroReport, 4: 11871190.

7. Stamler JS, Simon DI \& Osborne JA (1992). S-Nitrosylation of proteins with nitric oxide: synthesis and characterization of biologically active compounds. Proceedings of the National Academy of Sciences, USA, 89: 444-448.
8. Maggio R, Fumagalli F, Donati E, Barbier P, Racagni G, Corsini GU \& Riva M (1995). Inhibition of nitric oxide synthase dramatically potentiates seizures induced by kainic acid and pilocarpine in rats. Brain Research, 679: 184-187.

9. Starr MS \& Starr BS (1993). Paradoxical facilitation of pilocarpine-induced seizures in the mouse by MK-801 and the nitric oxide synthesis inhibitor L-NAME. Pharmacology, Biochemistry and Behavior, 45: 321-325.

10. De Sarro G, Di Paola ED, De Sarro A \& Vidal MJ (1993). L-Arginine potentiates excitatory amino acid-induced seizures elicited in the deep prepiriform cortex. European Journal of Pharmacology, 230: 151-158.

11. Osonoe K, Mori N, Suzuki K \& Osonoe M (1994). Antiepileptic effects of inhibitors of nitric oxide synthase examined in pentylenetetrazol-induced seizures in rats. Brain Research, 663: 338-340.

12. Penix LRP, Davies $W$ \& Subramaniam $S$ (1994). Inhibition of NO synthase increases the severity of kainic acid-induced seizures in rodents. Epilepsy Research, 18: 177-184.
13. Wang $Q$, Theard MA, Pelligrino DA, Baughman VL, Hoffman WE, Albrecht RF, Cwik M, Paulson OB \& Lassen NA (1994). Nitric oxide (NO) is an endogenous anticonvulsant but not a mediator of the increase in cerebral blood flow accompanying bicuculline-induced seizure in rats. Brain Research, 658: 192-198.

14. Mollace V, Bagetta G \& Nistico G (1991) Evidence that L-arginine possesses proconvulsant effects mediated through nitric oxide. NeuroReport, 2: 269-272.

15. Theard MA, Baughman VL, Wang $Q$, Pelligrino DA \& Albrecht RF (1995). The role of nitric oxide in modulating brain activity and blood flow during seizure. NeuroReport, 6: 921-924.

16. Mulsch A, Schray-Utz B, Mordvinteev PI, Vanin AF, Nielsen EO, Scheel-Kruger J \& Olesen SP (1994). Nitric oxide promotes seizure activity in kainate-treated rats. NeuroReport, 5: 2325-2328.

17. Bagetta G, lannone M, Scorsa AM \& Nistico G (1992). Tacrine induced seizures and brain damage in $\mathrm{LiCl}$-treated rats can be prevented by N-omega-nitro-L-arginine methyl ester. European Journal of Pharmacology, 213: 301-304. 
18. Rigaud-Monet AS, Heron A, Seylaz J \& Pinard $E$ (1995). Effect of inhibiting NO synthesis on hippocampal extracellular glutamate concentration in seizures induced by kainic acid. Brain Research, 673: 297-303.

19. Rundfeld C, Koch R, Richter A, Mevissen M, Gerecke U \& Löscher W (1995). Dosedependent anticonvulsant and proconvulsant effects of nitric oxide synthase inhibitors on seizure threshold in a cortical stimulation model in rats. European Journal of Pharmacology, 274: 73-81.

20. Choi DW (1993). Nitric oxide: foe or friend of injured brain? Proceedings of the $\mathrm{Na}$ tional Academy of Sciences, USA, 90: 9741-9743.

21. Änggard E (1994). Nitric oxide, mediator, murderer and medicine. Lancet, 343: 1199-1206.

22. Schuman EM \& Madison DV (1994). Nitric oxide and synaptic function. Annual Review of Neuroscience, 17: 153-183.

23. Lipton SA (1993). Prospects for clinically tolerated NMDA antagonists: open channel blockers and alternative redox states of nitric oxide. Trends in Neuroscience, 16: 527-532.

24. Snyder SH (1993). Janus face of nitric oxide. Nature, 364: 577.

25. Yamamoto S, Golanov EV, Berger SB \& Reis DJ (1992). Inhibition of nitric oxide synthesis increases focal ischaemic infarction in rat. Journal of Cerebral Blood Flow Metabolism, 12: 717-726.

26. Huang Z, Huang PL, Panahian N, Dalkara T, Fishman MC \& Moscowitz MA (1994). Effects of cerebral ischaemia in mice deficient in neuronal nitric oxide synthase. Science, 265: 1883-1885.

27. Turski WA, Cavalheiro EA, Schwartz $M$, Czuczwar SJ, Kleinrok Z \& Turski L (1991). Limbic seizures produced by pilocarpine in rats: behavioral, electroencephalographic and neuropathological study. Brain Research, 9: 315-356.

28. Cavalheiro EA, Leite JP, Bortolotto ZA, Turski WA, Ikonomidou C \& Turski L (1991). Long-term effects of pilocarpine in rats: structural damage of the brain triggers kindling and spontaneous recurrent seizures. Epilepsia, 32: 778-782.

29. Jobe PC, Mishra PK, Adams-Curtis LE, Ho Ko K \& Dailey JW (1994). The GEPR model of the epilepsies. In: Malafose A, Genton P, Hirsch E, Marescaux C, Broglin $\mathrm{D}$ \& Bernasconi $\mathrm{R}$ (Editors), Idiopathic Generalized Epilepsies: Clinical, Experimental and Genetic Aspects. John Libbey \& Company Ltd., London.
30. Garcia-Cairasco N, Terra VC \& Doretto MC (1993). Midbrain substrates of audiogenic seizures in rats. Behavioral Brain Research, 58: 57-67.

31. Lemos T \& Cavalheiro EA (1995). Suppression of pilocarpine-induced status epilepticus and the late development of epilepsy in rats. Experimental Brain Research, 102: 423-428.

32. Gale K (1989). GABA in epilepsy: The pharmacological basis. Epilepsia, 30 (Suppl): S1-S11.

33. Racine RJ (1972). Modification of seizure activity by electrical stimulation. II. Motor seizure. Electroencephalography and Clinical Neurophysiology, 32: 281-294.

34. Garcia-Cairasco N, Wakamatsu H, Oliveira JAC, Gomes ELT, Del Bel EA \& Mello LEAM (1996). Neuroethological and morphological (Neo-Timm staining) correlates of limbic recruitment during the development of audiogenic kindling in seizure susceptible Wistar rats. Epilepsy Research, 26: 177-192.

35. Leite JP, Bortolotto ZA \& Cavalheiro E (1990). Spontaneous recurrent seizures in rats: an experimental model of partial epilepsy. Neuroscience and Biobehavioral Reviews, 14: 511-517.

36. Izumi Y, Benz AM, Clifford DB \& Zorumski CF (1992). Nitric oxide inhibitors attenuate $\mathrm{N}$-methyl-D-aspartate excitotoxicity in rat hippocampal slices. Neuroscience Letters, 135: 227-230.

37. Dwyer MA, Bredt DS \& Snyder SH (1991). Nitric oxide synthase: irreversible inhibition by $\mathrm{L}-\mathrm{NG}$-nitroarginine in brain in vitro and in vivo. Biochemical and Biophysical Research Communications, 176: 11361141.

38. Salter M, Duffy C \& Hazelwood R (1995). Determination of brain nitric oxide synthase inhibition in vivo: Ex vivo assays of nitric oxide synthase can give incorrect results. Neuropharmacology, 34: 327-334.

39. Morley JE \& Flood JF (1991). Evidence that nitric oxide modulates food intake in mice. Life Sciences, 49: 707-711.

40. Chapman PF, Atikins CM, Allen MT, Haley JE \& Steinmetz JE (1992). Inhibition of nitric oxide synthesis impairs two forms of learning. NeuroReport, 3: 567-570.

41. Guimarães FS, Aguiar JC, Del Bel EA \& Ballejo G (1994). Anxiolytic effect of nitric oxide synthase inhibitors microinjected into the dorsal central grey. NeuroReport, 5: 1929-1932.

42. Marras RA, Martins AP, Del Bel EA \& Guimarães FS (1995). L-NOARG, an inhibitor of nitric oxide synthase induces catalepsy in mice. NeuroReport, 7: 158-160.
43. Lino de Oliveira C, Del Bel EA \& Guimarães FS (1997). Effects of LNOARG on plus-maze performance in rats. Pharmacology, Biochemistry and Behavior, 56: 55-59.

44. Itzhak Y (1993). Nitric oxide synthesis inhibitors abolish cocaine-induced toxicity in mice. Neuropharmacology, 32: 10691070.

45. Velisek L, Kusá R, Kulovaná M \& Mares $P$ (1990). Excitatory amino acid antagonists and pentylenetetrazol-induced seizures during ontogenesis. Life Sciences, 46: 1349-1357.

46. Kirkby RD, Forbes RA \& Subramaniam S (1996). Modification of kainate-induced behavioral and electrographic seizures following inhibition of nitric oxide synthase in mice. Epilepsy Research, 24: 79-90.

47. Terra VC \& Garcia-Cairasco N (1994). NMDA-dependent audiogenic seizures are differentially regulated by inferior colliculus subnuclei. Behavioural Brain Research, 62: 29-39.

48. Grassi C, Santarelli R, Nistico S, Bagetta G \& Azzena GB (1995). Possible modulation of auditory middle latency response by nitric oxide in the inferior colliculus of anaesthetized rats. Neuroscience Letters, 196: 213-217

49. Iannone M, Del Duca C, Granato T, Rispoli $V$ \& Nistico G (1996). Sound-evoked electrocortical desynchronization is inhibited by $\mathrm{N}^{\omega}$-nitro-L-arginine-methyl ester microinfused into the inferior colliculi in rats. Electroencephalography and Clinical Neurophysiology, 99: 57-62.

50. Iga $Y$, Yoshioka $M$, Togashi $H$ \& Saito $H$ (1993). Inhibitory action of N-nitro-L-arginine methyl ester on in vivo long-term potentiation in the dentate gyrus. European Journal of Pharmacology, 238: 395398.

51. Kawabata A, Umeda N \& Takagi H (1993) L-Arginine exerts a dual role in nociceptive processing in the brain: involvement of the kyotorphin-met-enkephalin pathway and NO-cyclic-GMP pathway. British Journal of Pharmacology, 109: 73-79.

52. Proctor MR, Fornai F, Afshar JKB \& Gale $K$ (1997). The role of nitric oxide in focallyevoked seizures. Neuroscience, 76: 12311236.

53. Löscher W \& Hönack D (1990). High doses of memantine (1-amino-3,5dimethyladamantane) induce seizure in kindled but not in non-kindled rats. Archives of Pharmacology, 341: 476-481. 